\title{
Complaining Behavior Intentions dan beberapa Antesendennya: Peran Gender sebagai Variabel Moderasi
}

\author{
Dyah Astarini \\ Fakultas Ekonomi dan Bisnis Universitas Trisakti \\ Kampus A, Jl. Kyai Tapa No.1, Grogol, Jakarta Barat 11440, Indonesia \\ diah.astarini@trisakti.ac.id \\ Luki Adiati Pratomo \\ Fakultas Ekonomi dan Bisnis Universitas Trisakti \\ Kampus A, Jl. Kyai Tapa No.1, Grogol, Jakarta Barat 11440, Indonesia \\ luki.adiati@trisakti.ac.id
}

Diterima: 10-06-2020

Disetujui: 09-10-2020

Dipublikasi: 30-01-2021

\begin{abstract}
ABSTRAK
Penelitian ini bertujuan untuk menganalisis faktor-faktor yang mempengaruhi complaining behavior intentions yang dimoderasi oleh gender. Metode pengumpulan data dilakukan dengan penyebaran kuesioner baik secara langsung maupun melalui online. Jumlah responden yang dianalisa adalah 225. Pengujian dilakukan dengan menggunakan SEM. Hasil penelitian ditemukan bahwa faktor-faktor yang mempengaruhi complaining behavior adalah attitudes towards complaining, the level of dissatisfaction, dan the importance of the situation. Lebih lanjut, penelitian menunjukkan bahwa gender (jenis kelamin) memoderasi hubungan Attitudes towards complaining, level of dissatisfaction dan importance of the situation terhadap complaining behavior intention. Untuk penelitian selanjutnya disarankan untuk meneliti industri jasa lain seperti hotel, airline atau perbankan dan menambahkan variabel perceived justice.
\end{abstract}

Kata Kunci:

Attitudes towards complaining, level of information, level of dissatisfaction, the importance of the situation, likelihood of success, complaining behavior intention, gender

\begin{abstract}
This research aims to analyze the factors that affect the complaining behavior intentions that are moderated by gender. The data collection method is done by distribution the questionnaire, directly and online and finally used 225 respondents. Hypothesis testing is using SEM. The results of the study were found that the factors affecting complaining behavior were attitudes towards complaining, the level of dissatisfaction, and the importance of the situation. Furthermore, these studies have shown that gender moderates the relationships between attitude towards complaining, level of dissatisfaction, and importance of the situation against complaining behavior intention. For further study, it is advised to research other services industries such as hotels, airline, or banking and add perceived justice variabels.
\end{abstract}

Keywords:

Attitudes towards complaining, level of information, level of dissatisfaction, the importance of the situation, likelihood of success, complaining behavior intention, gender 


\section{PENDAHULUAN}

Perkembangan bisnis restoran di Indonesia sangat pesat, sehingga menyebabkan persaingan juga semakin ketat (Wulandari, 2015). Oleh karenanya pengusaha jasa restoran harus berusaha menyampaikan pelayanan sebaik-baiknya dan menghindari kesalahan, sementara ternyata tidak mudah juga bagi restoran untuk mencapai zero defect (Huang \& Lin, 2011).

Kegagalan pelayanan sangat tidak disukai konsumen dan dapat menimbulkan keluhan dari mereka, sehingga restoran harus memahami perilaku konsumen ketika menyampaikan keluhan (Jin, 2010). Ketika kegagalan pelayanan terjadi, ada tiga kemungkinan perilaku konsumen yaitu tidak mengeluh pada perusahaan tapi justru menyampaikan pada teman dan saudaranya (private response), mengeluh pada perusahaan (complaining response) dan menyampaikan berita negatif pada pihak ketiga (third party response) seperti Yayasan konsumen (Velázquez et al., 2010).

Kegagalan pelayanan dapat menyebabkan ke tidak-puasan konsumen, tetapi ternyata tidak selalu mendorong konsumen untuk langsung mengeluh pada perusahaan (Jin, 2010; J. Singh, 1988). Masih ada faktor-faktor lain yang pada akhirnya akan mendorong konsumen untuk mengeluhkan masalah yang mereka hadapi pada perusahaan (Oh, 2006). Menurut beberapa peneliti, ada beberapa faktor yang dapat mendorong konsumen menyampaikan keluhan seperti attitude toward complaining, the level of information and experience, the level of dissatisfaction, the importance of the situation dan the likehood of success with the complaint, prior experience, dan consumer alinienation (Jin, 2010; Oh, 2006; J. Singh, 1988; J. Singh \& Wilkes, 1996; Velázquez et al., 2010).

Selain faktor-faktor tersebut, masih ada beberapa perbedaan individu yang dapat menyebabkan timbulnya respon konsumen yang berbeda seperti budaya, personality dan jenis kelamin (Ayas et al., 2016; Faqih \& Jaradat, 2015; Gruber et al., 2009; Song et al., 2017). Jenis kelamin terbukti merupakan salah satu faktor yang dapat mempengaruhi perilaku konsumen, begitu juga ketika konsumen mengalami kekecewaan terhadap perusahaan ternyata respon mereka berbeda (Gruber et al., 2009; Song et al., 2017). Hal itu mendorong kemungkinan bahwa jenis kelamin dapat memoderasi pengaruh berbagai faktor yang menjadi anteseden terhadap complaining behavior intention.

Urgensi penelitian ini adalah untuk mengetahui peranan jenis kelamin dalam memoderasi keinginan konsumen dalam menyampaikan keluhan, mengingat sampai saat ini penelitian mengenai peranan jenis kelamin masih menghasilkan pendapat yang berbeda-beda. Misalnya 
penelitian Tifferet \& Herstein, (2012) yang menemukan bahwa wanita lebih impulsive dalam melakukan pembelian, sementara Gangai \& Agrawal (2016) justru sebaliknya.

Berdasarkan teori diatas, maka studi ini akan meneliti pengaruh beberapa faktor yang menjadi anteseden terhadap complaining behavior intention dan mengukur peranan jenis kelamin sebagai variabel yang memoderasinya.

\section{TINJAUAN TEORI}

\section{Complaining Behavior Dimension}

Ketika konsumen mengalami masalah akibat penyampaian jasa yang salah, maka terdapat dua macam respon yaitu mereka menyampaikan keluhan ataupun tidak menyampaikan keluhan (J. Singh, 1988). Keluhan konsumen dapat disampaikan langsung pada perusahaan (voice) dengan tujuan agar perusahaan memperbaiki kegagalan tersebut (J. Blodgett et al., 2015; Funches et al., 2009; Levesque \& McDougall, 1996). Sedangkan kemungkinan lainnya adalah menyampaikan pada pihak ketiga seperti Yayasan Konsumen atau pengadilan (J. Singh, 1988; V. Singh et al., 2016). Selain itu, ada juga konsumen yang tidak mengeluh atau disebut juga private responses, mereka diam saja walaupun tidak puas, tetapi ada kemungkinan mereka akan menyampaikan kepada teman dan kerabatnya masalah yang terjadi sehingga akan menimbulkan berita negatif (Funches, 2011; Funches et al., 2009).

\section{Antecedents of Complaining Behavior}

Walaupun konsumen mengalami masalah dengan penyedia jasa, ternyata tidak serta merta mereka akan menyampaikan keluhan pada perusahaan (J. Singh, 1988). Peneliti lain, seperti Jin, (2010) menguraikan bahwa konsumen akan membandingkan manfaat dan pengorbanan yang harus dilakukan untuk menyampaikan keluhan. Sementara Meng, Wang, Peters, \& Lawson (2010) mengatakan bahwa masih ada beberapa faktor lain seperti seberapa besar kemungkinan sukses keluhan ini disampaikan, emosi negatif yang dirasakan konsumen, seberapa berat kekecewaan konsumen, dan tingkat kerepotan dalam prosedur penyampaian masalah.

Selanjutnya Velázquez et al., (2010) menjelaskan bahwa terdapat terdapat 2 (dua) faktor utama yang mendorong konsumen untuk menyampaikan keluhan, yaitu General determining factors dan Specific determining factors. Di luar faktor pribadi tersebut, masih ada faktorfaktor khusus yang terdiri dari tingkat ketidakpuasan, pentingnya situasi yang dihadapi konsumen dan juga seberapa besar kemungkinan mereka akan sukses dalam menyampaikan keluhan (Velázquez et al., 2010). 


\section{Peranan Jenis Kelamin (Gender) sebagai Moderator}

Jenis kelamin merupakan salah satu faktor yang dalam berbagai penelitian terbukti mempunyai pengaruh dalam pengambilan keputusan konsumen, baik untuk melakukan pembelian ataupun pemesanan (Ye et al., 2017; Zhang et al., 2018). Begitu juga ketika konsumen menyampaikan keluhan pada perusahaan, ternyata wanita cenderung menggunakan emosi lebih banyak dibanding pria, sementara konsumen laki-laki lebih ingin agar masalah segera selesai tanpa harus marah-marah (Gruber et al., 2009). Tahir, Buttar, \& Ahmad (2018) juga menjelaskan bahwa jenis kelamin ternyata memoderasi pengaruh public complaint terhadap defection.

\section{Pengembangan Hipotesis}

\section{Pengaruh Attitudes Towards Complaining terhadap Complaining Behavior Intention}

Attitudes towads complaining merupakan kecenderungan umum konsumen ketika menghadapi masalah, mereka akan mengevaluasi apakah lebih baik menyampaikan keluhan atau lebih baik tidak menyampaikan keluhan (de Matos, Henrique, \& de Rosa, 2013; Singh \& Wilkes, 1996). Berdasarkan penelitian Singh \& Wilkes (1996) pada industri perbankan dan perbaikan kendaraan, ditemukan bahwa semakin kuat sikap konsumen terhadap keluhan, maka semakin besar pula keinginan konsumen mengeluhkan masalahnya pada perusahaan. Begitu juga de Matos et al., (2013) menegaskan bahwa konsumen yang memiliki attitudes towards complaining yang tinggi akan lebih berkeinginan untuk menyampaikan keluhannya pada penyedia jasa yang mengecewakan mereka. Pemikiran diatas menjadi dasar hipotesis sebagai berikut:

H1: Attitudes towards complaining mempunyai pengaruh positif terhadap complaining behavior intention

\section{Pengaruh the Level of Information and or Experience terhadap Complaining Behavior Intention}

Ketika konsumen mengalami kegagalan pelayanan, maka pengalaman mereka sebelumnya dan juga pengetahuan mereka akan adanya jasa pengganti, kualitas produk atau jasa yang dibeli maupun proses penyampaian keluhan akan sangat mempengaruhi keinginan mereka untuk mengeluhkan masalah yang dihadapi kepada penyedia jasa (Singh \& Wilkes, 1996), Huppertz (2014) juga menjelaskan bahwa salah satu faktor yang membentuk keinginan konsumen dalam mengeluhkan masalah adalah pengalaman mereka. Dengan demikian dibentuklah hipotesis sebagai berikut: 
$\mathrm{H} 2$ : The level of information and or experience mempunyai pengaruh positif terhadap complaining behavior intention

\section{Pengaruh the Level of Dissatisfaction terhadap Complaining Behavior Intention}

Tingkat ketidak puasan konsumen merupakan salah satu faktor yang dapat mendorong keinginan konsumen untuk menyampaikan keluhannya (Velázquez et al., 2010). Semakin menyulitkan persoalan yang timbul dalam pandangan konsumen (the severity of the service problem), maka semakin besar pula keinginan mereka untuk memberi tahu perusahaan (Bolfing, 1989). Begitu juga penelitian pada industri ritel (eceran) yang dilakukan (Chelminski \& Coulter, 2011) membuktikan bahwa ketika konsumen merasa masalah yang dihadapi sangat signifikan, maka mereka semakin merasa perlu menyampaikan keluhannya. Berdasarkan teori diatas, maka hipotesis yang dikembangkan adalah:

H3: The level of dissatisfaction mempunyai pengaruh positif terhadap complaining behavior intention

\section{Pengaruh the Importance of The Situation terhadap Complaining Behavior Intention}

Kegagalan pelayanan tidak selalu menimbulkan keinginan untuk mengeluhkannya, tetapi apabila konsumen menganggap jasa tersebut sangat penting (Importance of the situation), maka konsumen merasa urgensinya untuk menyampaikan keluhan menjadi besar (Levesque \& McDougall, 1996). Begitu juga ketika harga jasa tersebut mahal, maka konsumen merasa jasa tersebut sangat penting sehingga kegagalan menjadi masalah besar yang harus dikeluhkan ke penyedianya (Tsarenko \& Rooslani Tojib, 2011). Apalagi ketika untuk melakukan pembelian jasa tersebut memerlukan keterlibatan konsumen yang sangat tinggi, maka jasa tersebut tentu dirasa sangat penting bagi konsumen dan akhirnya bila terjadi masalah, konsumen merasa sangat terdorong untuk menyampaikan keluhannya (Hamzelu et al., 2017). Berbagai hasil penelitian tersebut menjadi dasar dari hipotesis sebagai berikut:

H4: The importance of the situation mempunyai pengaruh positif terhadap complaining behavior intention

\section{Pengaruh the Likelihood of Success with the Complaint terhadap Complaining Behavior}

\section{Intention}

Pada saat konsumen mengalami pelayanan yang mengecewakan, mereka akan mempunyai intensi untuk menyampaikan kekesalannya pada perusahaan, khususnya apabila konsumen tersebut merasa bahwa keluhan tersebut akan menghasilkan manfaat bagi mereka (Singh, 1988; Singh, 1991). Likelihood of success with the complaint menurut Velázquez et 
al., (2010) adalah persepsi pelanggan tentang seberapa jauh kemungkinannya penyedia jasa menanggapi keluhan yang mereka sampaikan, apakah karyawan perusahaan cukup sensitif dalam menangani keluhan, bagaimana proses menyampaikan keluhan dan manfaat apa yang akan diperolehnya. Semakin besar kemungkinan suksesnya, maka semakin besar pula keinginan konsumen menyampaikan masalah yang dihadapinya pada penyedia jasa (Jin, 2010; Velázquez et al., 2010). Berdasarkan uraian tersebut, maka disusunlah hipotesis :

H5: The likelihood of success with the complaint mempunyai pengaruh positif terhadap complaining behavior intention

\section{Peranan Gender (Jenis Kelamin) sebagai Variabel Moderasi pada Hubungan antara beberapa Anteseden dari Complaining Behavior Intention}

Wanita dan pria pada dasarnya berbeda, dan hal tersebut diakui dan telah dibuktikan pada penelitian-penelitian mengenai perilaku konsumen seperti Frank, Enkawa, \& Schvaneveldt (2014) yang menemukan bahwa citra merek publik memberikan pengaruh terhadap kepuasan dan keinginan untuk membeli kembali pada konsumen wanita. Begitu juga wanita ternyata lebih aktif menanggapi iklan melalui SMS dibandingkan pria (Leppäniemi \& Karjaluoto, 2008). Pada industri eceran, ditemukan bahwa pria lebih loyal pada perusahaan rantai eceran sementara wanita lebih loyal pada perusahaan eceran yang berdiri sendiri karena mereka lebih menyukai hubungan yang sifatnya pribadi (Audrain-Pontevia \& Vanhuele, 2016).

Sedangkan penelitian pada perilaku konsumen dalam menyampaikan keluhan, masih sangat terbatas, salah satunya adalah Gruber et al., (2009) yang membedakan perilaku konsumen wanita dan pria dalam interaksi konsumen dengan penyedia jasa. Gruber et al., (2009) menjelaskan bahwa wanita cenderung lebih emosional dibanding pria ketika menghadapi masalah sehingga memerlukan perhatian khusus dari penyedia jasa untuk menenangkan mereka, sementara konsumen pria lebih mementingkan penanganan yang cepat. Sedangkan Song et al., (2017) dalam penelitiannya mengenai respon wanita ketika mereka tidak puas terhadap kegagalan produk, menemukan bahwa ketika konsumen wanita merasa bahwa telah menyebabkan terjadi kegagalan yang sangat berat pada produk yang mereka beli, maka ketidak puasannya menjadi lebih besar.

Pada industri jasa, Stratemeyer \& Geringer (2014) menjelaskan bahwa konsumen wanita segera mengeluhkan kegagalan pelayanan pada penyedia jasa dan meminta agar segera diperbaiki, permohonan maaf serta kompensasi. Berdasarkan berbagai hasil penelitian diatas, terlihat bahwa wanita dan pria memang mengevaluasi berbagai hal secara berbeda, begitu juga sangat mungkin jenis kelamin akan mempunyai peranan yang berbeda terhadap pengaruh 
Attitudes towards complaining, Level of information and/or experience, Level of dissatisfaction, Importance of the situation dan Likelihood of success with the complaint terhadap complaining behavior intention sehingga studi ini mengembangkan hipotesis sebagai berikut:

H6: Hubungan Attitudes towards complaining dan complaining behavior intention dimoderasi oleh gender (jenis kelamin)

H7: Hubungan The level of information and complaining experience dan complaining behavior intention dimoderasi oleh gender (jenis kelamin)

H8: Hubungan The level of dissatisfaction dan complaining behavior intention dimoderasi oleh gender (jenis kelamin)

H9: Hubungan the impotance of situation dan complaining behavior intention dimoderasi oleh gender (jenis kelamin)

H10: Hubungan The likelihood of success with complaint dan complaining behavior intention dimoderasi oleh gender (jenis kelamin)

\section{Kerangka konseptual}

Konsumen yang mengalami masalah dengan penyedia jasa dapat merespon dalam bentuk private responses (respon pribadi berupa diam saja ataupun menyampaikan pada temantemannya), complaining responses (menyampaikan keluhan pada perusahaan) dan complains to third parties atau menyampaikan keluhan pada pihak ketiga (Singh, 1988; Velázquez et al., 2010).

Perusahaan jasa perlu memahami bahwa terdapat beberapa faktor yang dapat mempengaruhi keinginan konsumen menyampaikan keluhan (Singh, 1988; Singh, 1991; Velázquez et al., 2010). Sikap konsumen terhadap keinginan mengeluh dan juga seberapa banyak pengalaman maupun pengetahuan konsumen mengenai masalah yang terjadi akan mendorong keinginan konsumen untuk menyampaikan keluhan pada perusahaan (AguilarRojas et al., 2015; de Matos et al., 2013; Huppertz, 2014). Sedangkan seberapa besar ketidak puasan yang dirasakan konsumen, tingkat pentingnya masalah yang terjadi dan seberapa mungkin keluhan tersebut ditanggapi perusahaan akan mempengaruhi keinginan konsumen untuk mengeluhkan persoalan mereka (J. Blodgett et al., 2015; Edvardsson et al., 2011; McQuilken, 2009; Velázquez et al., 2010).

Jenis kelamin konsumen merupakan faktor yang harus diperhitungkan, mengingat bahwa faktor ini dapat mempengaruhi perilaku konsumen, baik dalam melakukan pembelian, pemesanan hotel, bahkan juga dalam menyampaikan keluhan (Gruber et al., 2009; Hamzelu et 
al., 2017; Tahir et al., 2018). Berdasarkan pemikiran diatas, maka penelitian ini akan melihat peranan jenis kelamin dalam memoderasi pengaruh Attitudes towards complaining, Level of information and/or experience, Level of dissatisfaction, Importance of the situation dan Likelihood of success with the complaint terhadap keinginan konsumen menyampaikan keluhan (complaining behavior intention).

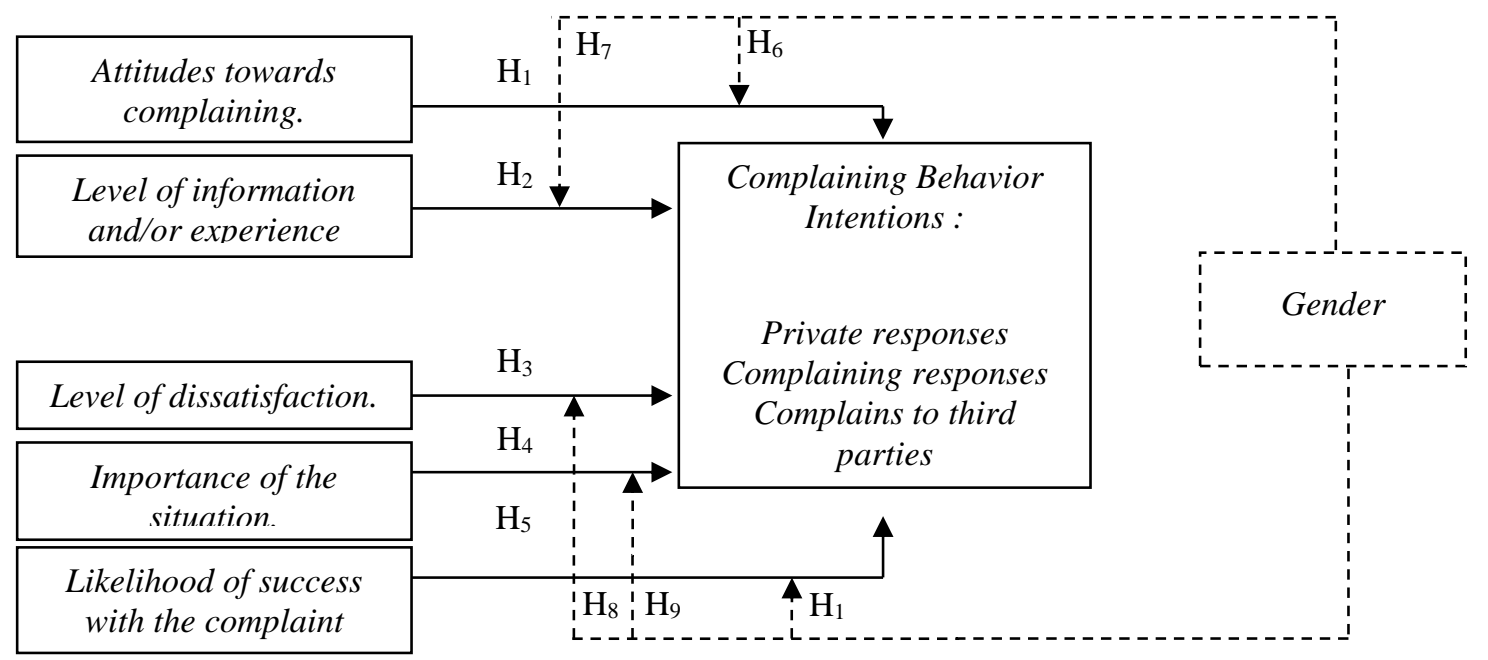

Gambar 1. Kerangka konseptual

\section{METODE RISET}

Penelitian ini dirancang untuk menguji hipotesis dengan unit analisis individu, khususnya konsumen restoran yang pernah mengalami kegagalan pelayanan dan menyampaikan keluhan. Untuk memastikan bahwa responden yang diperoleh sesuai kriteria, maka pada bagian pertama kuesioner terdapat beberapa pertanyaan yang akan menyaring calon responden. Apabila calon responden tidak mempunyai pengalaman kegagalan dengan sebuah restoran dan juga tidak menyampaikan keluhan, maka mereka tidak dapat menjawab pertanyaan bagian kedua. Selanjutnya data akan diolah dan dianalisis menggunakan Structural Equation Modelling (SEM). Penelitian ini menggunakan SEM sebagai alat analis karena mampu menguji penelitian yang kompleks dan banyak variabel secara simultan (Hair et al., 2019).

Variabel independen terdiri dari Attitudes towards complaining, Level of information and/or experience, Level of dissatisfaction, Importance of the situation dan Likelihood of success with the complaint dan variabel dependent adalah complaining behavior intention.

Alat ukur untuk variabel attitude toward complaining terdiri dari dua indikator yang, merupakan modifikasi dari Blodgett, Granbois, \& Walters (1993), salah satunya adalah "Ketika mendapatkan masalah dengan sebuah produk, walaupun murah, konsumen selalu 
menyampaikan keluhan dan mengharapkan pengganti uang (refund) atau mendapatkan penggantian produk".

Selanjutnya variabel level of information/experience terdiri dari dua indikator yang di adaptasi dari penelitian Singh, 1988 (1990), sebagai contoh: "konsumen paham mengenai hakhak konsumen”. Untuk variabel the level of dissatisfaction, penelitian ini menggunakan empat indikator yang diadaptasi dari Velázquez et al., (2010), dimana salah satunya adalah "ternyata makan di restoran ini bukanlah ide yang bagus". Sedangkan variabel The importance of the situation, merupakan modifikasi dari studi yang dilakukan Maxham \& Netemeyer (2002), terdiri dari tiga indikator, salah satu contohnya adalah "dibandingkan dengan berbagai kunjungan saya ke banyak restoran, kunjungan saya ke restoran ini sebenarnya sangat penting bagi saya". Pada variabel The likelihood of success with the complaint adalah modifikasi dari penelitian Blodgett et al., (1993), terdiri dari tiga indikator, salah satunya yaitu "seberapa besar kemungkinannya restoran ini akan mencoba menyelesaikan masalah anda?". Akhirnya, variabel complaining behavior intention terdiri dari sembilan indikator dan merupakan adaptasi dari Velázquez et al., (2010), beberapa kuesioner yang digunakan adalah: "Saya akan mendiskusikan masalah saya dengan manajer restoran; saya akan menceritakan pengalaman buruk di restoran ini kepada teman dan keluarga saya, dan saya akan menyampaikan masalah yang saya hadapi di restoran ini pada Yayasan Lembaga Konsumen”.

Pengambilan sampel dilakukan dengan prosedur non-probability sampling dengan tehnik purposive sampling karena jumlah populasi yang tidak bisa ditentukan (Sekaran dan Bougie, 2013). Purposive sampling mengharuskan peneliti menentukan kriteria yang jelas mengenai responden yang dapat digunakan, dan pada studi ini kriterianya adalah pelanggan yang pernah makan di sebuah restoran dan mengalami kekecewaan akibat kesalahan yang dilakukan restoran dalam jangka waktu enam bulan terakhir. Jumlah responden yang diperoleh adalah 275 yang terdiri dari 150 melalui wawancara langsung dan 125 melalui google form. Setelah dilakukan pemeriksaan, maka jumlah kuesioner yang dapat digunakan adalah 225.

Karakteristik responden pada penelitian ini dilihat dari jenis kelamin terlihat bahwa jumlah wanita dan pria hampir seimbang yaitu wanita 112 orang dan pria 113 orang. Sedangkan dilihat dari usia, terbanyak adalah responden yang berusia antara 21 sampai 30 tahun yaitu 160 orang, lalu responden terbanyak adalah pelajar dan mahasiswa yang berjumlah 117 orang. Terakhir, responden terbanyak adalah yang mengunjungi restoran keluarga yaitu 101 orang dan keluhan yang tertinggi adalah karena pelayanan restoran yang lamban yaitu 60 orang. 


\section{Uji Validitas dan Reliabilitas}

Uji validitas menggunakan Confirmatory Factor Analisys (CFA) dengan kriteria penilaian diatas faktor loading 0,40. Hal tersebut sesuai dengan penjelasan Hair et al., (2019) bahwa nilai faktor loading untuk jumlah 200 dan lebih responden adalah 0.40. Berdasarkan hasil uji validitas tersebut, maka semua indikator pada masing-masing variabel dinayatakan valid karena nilai faktor loading nya melebih 0.40. Selain uji validitas, dilakukan juga uji reliabilitas dengan menggunakan inter-item consistensy dengan Cronbach's Coefficient Alpha yang nilainya diatas 0.6 (Sekaran \& Bougie, 2013). Berdasarkan hasil uji reliabilitas, maka disimpulkan bahwa semua variabel dalam studi ini reliabel karena mempunyai nilai diatas 0.6.

\section{Structural Equation Model (SEM)}

Sebelum melakukan pengujian kesesuaian model terlebih dahulu dilakukan normality assessment untuk mengetahui sebaran data pada sebuah kelompok data atau variabel, apakah sebaran data tersebut berdistribusi normal atau tidak. Uji normalitas ini dapat dilihat pada nilai nilai Critical Ratio (CR) dari skewness dan kurtosisnya. Jika nilai CR antara rentang 2.58 sampai dengan $2.58( \pm 2.58)$ pada tingkat signifikansi $1 \%(0.01)$, dapat disimpulkan bahwa bahwa data berdistribusi normal baik univariate maupun multivariate. Berdasarkan hasil uji normalitas pada model 1 dan model 2, semua nilai CR berada pada rentang -2.58 sampai dengan 2.58. Sehingga kesimpulannya adalah data pada studi ini berdistribusi normal.

Selanjutnya dilakukan pengujian kesesuaian model (goodness-of-fit model) yang terdiri dari dua kali pengujian. Hasil pengujian Model pertama untuk melihat hubungan langsung antara variabel dependent dan independent.

Tabel 1. Pengujian Kesesuaian Model (Model I)

\begin{tabular}{cccc}
\hline Pengukuran & Hasil Pengukuran & $\begin{array}{r}\text { Batas Penerimaan yang } \\
\text { disarankan }\end{array}$ & Keputusan \\
\hline RMSEA & 0.046 & $0.03-0.08$ & Goodness of fit \\
GFI & 0.950 & $\geq 0.90$ & Goodness of fit \\
NFI & 0.945 & $\geq 0.90$ & Goodness of fit \\
TLI & 0.963 & $\geq 0.90$ & Goodness of fit \\
RFI & 0.893 & $\geq 0.90$ & Goodness of fit \\
CFI & 0.981 & $\geq 0.90$ & Goodness of fit \\
IFI & 0.981 & $\geq 0.90$ & Goodness offit \\
\hline
\end{tabular}

Sumber: Hasil olah data, 2020

Menurut Hair et al., (2019) nilai RMSEA yang ideal adalah 0.03-0.08. Hasil pengujian pada model pertama ini diperoleh nilai 0.046 pada RMSEA. Berarti nilai RMSEA dapat dinyatakan ideal karena berada diantara $0.03-0.08$. Bila berdasarkan Incremental Measures, suatu model dinyatakan lolos jika hasilnya $\geq 0.90$. Hasil yang diperoleh dari incremental 
measures seluruhnya diatas 0.90 berarti lolos uji. Dengan demikian dapat disimpulkan model pertama ini lulus uji Goodness of Fit.

Tabel 2. Pengujian Kesesuaian Model (Model II)

\begin{tabular}{cccc}
\hline Pengukuran & Hasil Pengukuran & $\begin{array}{c}\text { Batas Penerimaan yang } \\
\text { disarankan }\end{array}$ & Keputusan \\
\hline RMSEA & 0.070 & $0.03-0.08$ & Goodness of fit \\
GFI & 0,851 & $\geq 0.90$ & Goodness of fit \\
NFI & 0.836 & $\geq 0.90$ & Marginal of fit \\
TLI & 0.850 & $\geq 0.90$ & Goodness of fit \\
CFI & 0.903 & $\geq 0.90$ & Goodness offit \\
IFI & 0.907 & $\geq 0.90$ & Goodness of fit \\
\hline
\end{tabular}

Sumber: Hasil olah data, 2020

Setelah model pertama terbukti sesuai, maka dilakukan uji Goodness of Fit untuk Model kedua yaitu moderasi variabel dependent dan independent. Berdasarkan hasil uji, maka model kedua ini juga dinyatakan ideal karena nilai RMSEA model kedua sebesar 0.070 dan hasil incremental measures hampir seluruhnya memiliki nilai $\geq 0.90$ kecuali NFI yaitu sebesar 0.836 (marginal of fit). Dengan demikian, dapat dikatakan model kedua juga lulus uji Goodness of Fit.

\section{HASIL PENELITIAN DAN PEMBAHASAN}

\section{Statistik Deskriptif}

Data yang telah dikumpulkan dianalisa masing-masing variabelnya menggunakan mean dan standard deviasi. Tabel dibawah ini akan memperlihatkan hasil perhitungan statistik deskriptif untuk central tendency dari penelitian ini.

\section{Tabel 3. Statistik Deskriptif}

\begin{tabular}{lcc}
\hline Variabel & Mean & SD \\
\hline Level of information and/or experience & 3.81 & 0.70 \\
Level of dissatisfaction & 3.27 & 0.70 \\
Importance of the situation & 2.70 & 0.81 \\
Likelihood of success with the complaint & 3.20 & 0.74 \\
Complaining behavior intentions & 2.87 & 0.62 \\
$\quad$ Private Responses & 3.20 & 0.94 \\
Complaining Responses & 3.02 & 0.95 \\
Responses to third parties. & 2.31 & 0.97 \\
\hline
\end{tabular}

Sumber: Hasil olah data, 2020

Statistik deskriptif pada Tabel 1 mengukur mean dan standar deviasi menggunakan 5 skala likert yaitu 1 yang menggambarkan sangat tidak setuju dan 5 yang menggambarkan sangat setuju. Pada Tabel 1 dapat dilihat bahwa untuk variabel attitudes towards complaining memiliki nilai mean sebesar 2.98, hal ini menunjukkan bahwa rata-rata responden berpendapat bahwa apabila mereka menghadapi masalah dengan sebuah restoran, maka mereka perlu 
menyampaikan keluhan.

Selanjutnya, variabel Level of information and/or experience memiliki nilai mean (ratarata) sebesar 3.81 belum mencapai nilai standar 5 yang berarti baik sekali. Hal ini menunjukkan bahwa kebanyakan konsumen memiliki tingkat informasi dan pengalaman yang baik mengenai penyampaian keluhan.

Variabel Level of dissatisfaction memiliki nilai mean sebesar 3.27 dengan standard deviasi sebesar 0.70. Nilai 3.29 belum mencapai nilai 5 yang merupakan nilai maksimum. Hal ini menunjukkan bahwa banyak diantara responden yang merasa kurang puas dengan pelayanan di restoran yang mereka gunakan.

Lebih lanjut variabel Importance of the situation memiliki nilai mean sebesar 2.70 dengan standard deviasi sebesar 0.81. Hal ini menunjukkan bahwa rata-rata responden menganggap bahwa situasi/keadaan pada saat terjadi kegagalan layanan merupakan saat yang penting bagi konsumen, walaupun belum sangat penting.

Begitu juga variabel Likelihood of success with the complaint memiliki nilai mean sebesar 3.20 dengan standard deviasi sebesar 0.74. Hal ini menunjukkan bahwa rata-rata responden merasa cukup yakin bahwa keluhan yang akan disampaikan kepada restoran akan berhasil (terpenuhi) walaupun belum sangat yakin (5).

Variabel Complaining Behavior Intentions memiliki nilai sebesar 2.8 dengan standard deviasi sebesar 0.62. Hal ini menunjukkan bahwa rata-rata reponden lumayan berminat untuk melakukan komplen terhadap restoran yang dikunjungi baik secara pribadi (private response dengan nilai mean 3.20 dan standard deviasi 0.94 dan keluhan langsung kepada restoran (complaining response dengan nilai mean sebesar 3.02 dan standard deviasi 0.95, namun tidak ingin menyampaikan keluhan terhadap pihak lain (responses to third parties dengan nilai mean 2.31 dan standard deviasi 0.97 .

\section{Uji Hipotesis}

Selanjutnya dilakukan uji hipotesis, dengan syarat pengambilan keputusan uji hipotesis adalah dengan membandingkan besarnya $p$-value dengan level of significant sebesar $5 \%$ atau alpha 0,05 (Cooper \& Schindler, 2014). Pada tabel 4 akan menampilkan hasil uji hipotesis yang telah dilakukan. 
Tabel 4. Hasil keseluruhan pengujian hipotesis

\begin{tabular}{|c|c|c|c|c|c|c|}
\hline & Hipotesis & \multicolumn{2}{|c|}{ Estimate } & \multicolumn{2}{|c|}{$p$-value } & Keputusan \\
\hline $\mathrm{H}_{1}$ & $\begin{array}{c}\text { Attitudes towards complaining } \rightarrow \text { complaining } \\
\text { behavior intention }\end{array}$ & \multicolumn{2}{|c|}{0.354} & \multicolumn{2}{|c|}{0.000} & H1 didukung \\
\hline $\mathrm{H}_{2}$ & $\begin{array}{l}\text { The level of information and complaining } \\
\text { experience } \rightarrow \text { complaining behavior intention }\end{array}$ & \multicolumn{2}{|c|}{-0.230} & \multicolumn{2}{|c|}{0.008} & $\begin{array}{l}\mathrm{H} 2 \text { tidak } \\
\text { didukung }\end{array}$ \\
\hline $\mathrm{H}_{3}$ & $\begin{array}{c}\text { The level of dissatisfaction } \rightarrow \text { complaining } \\
\text { behavior intention }\end{array}$ & \multicolumn{2}{|c|}{0.413} & \multicolumn{2}{|c|}{0.000} & H3 didukung \\
\hline $\mathrm{H}_{4}$ & $\begin{array}{c}\text { The importance of the situation } \rightarrow \text { complaining } \\
\text { behavior intention }\end{array}$ & \multicolumn{2}{|c|}{0.108} & \multicolumn{2}{|c|}{0.045} & H4 didukung \\
\hline \multirow[t]{2}{*}{$\mathrm{H}_{5}$} & $\begin{array}{c}\text { The likelihood of success with the complaint } \rightarrow \\
\text { complaining behavior intention }\end{array}$ & \multicolumn{2}{|c|}{0.164} & \multicolumn{2}{|c|}{0.028} & H5 didukung \\
\hline & & $\mathbf{W}$ & $\mathbf{P}$ & $\mathbf{W}$ & $\mathbf{P}$ & \\
\hline $\mathrm{H}_{6}$ & $\begin{array}{l}\text { Hubungan Attitudes towards complaining dan } \\
\text { complaining behavior intention dimoderasi oleh } \\
\text { gender (jenis kelamin) }\end{array}$ & 0.194 & 0.272 & 0.001 & 0.000 & H6 didukung \\
\hline $\mathrm{H}_{7}$ & $\begin{array}{l}\text { Hubungan level of information and complaining } \\
\text { experience dan complaining behavior intention } \\
\text { dimoderasi oleh gender (jenis kelamin) }\end{array}$ & 0.044 & 0.138 & 0.293 & 0.083 & $\begin{array}{l}\text { H7 tidak } \\
\text { didukung }\end{array}$ \\
\hline $\mathrm{H}_{8}$ & $\begin{array}{l}\text { Hubungan level of dissatisfaction dan } \\
\text { complaining behavior intention dimoderasi oleh } \\
\text { gender (jenis kelamin) }\end{array}$ & .223 & .281 & .000 & 0.002 & H8 didukung \\
\hline $\mathrm{H}_{9}$ & $\begin{array}{l}\text { Hubungan importance of the situation dan } \\
\text { complaining behavior intention dimoderasi oleh } \\
\text { gender (jenis kelamin) }\end{array}$ & $0 . \overline{-}$ & 0.012 & 0.351 & 0.445 & $\begin{array}{l}\text { H9 tidak } \\
\text { didukung }\end{array}$ \\
\hline $\mathrm{H}_{10}$ & $\begin{array}{l}\text { Hubungan The likelihood of success with the } \\
\text { complaint dan complaining behavior intention } \\
\text { dimoderasi oleh gender (jenis kelamin) }\end{array}$ & 0.206 & 0.253 & 0.038 & 0.009 & H10 didukung \\
\hline
\end{tabular}

Sumber: Hasil olah data, 2020

Dapat dilihat dari tabel 3, bahwa terdapat pengaruh postif Attitudes towards complaining terhadap complaining behavior intention $(\mathrm{b}=0.354, \mathrm{p}<0.05)$, yang berarti $\mathrm{H} 1$ didukung. The level of information and complaining experience mempunyai pengaruh negatif terhadap complaining behavior intention $(\mathrm{b}=-0.230, \mathrm{p}<0.05)$, yang berarti $\mathrm{H} 2$ tidak didukung. The level of dissatisfaction mempunyai pengaruh positf terhadap complaining behavior intention $(\mathrm{b}=0.413, \mathrm{p}<0.05)$, yang berarti H3 didukung. Lebih lanjut, the importance of the situation mempunyai pengaruh positif terhadap complaining behavior intention $(b=0.108, p<0.05)$ yang berarti mendukung H4. Demikian pula the likelihood of success with the complaint mempunyai pengaruh positif terhadap complaining behavior intention $(b=0.164, p<0.05)$ yang berarti H5 didukung.

Pada H6,H7,H8, H9 dan H10 menguji peran Gender (jenis kelamin) sebagai moderator hubungan antar variabel yang diteliti. Adapun hasil yang diperoleh adalah bahwa gender (jenis kelamin) memoderasi hubungan Attitudes towards complaining dan complaining behavior intention ( $\mathrm{bw}=0.194, \mathrm{p}<0,05 ; \mathrm{b}=0.272, \mathrm{p}<0.05$ ) yang berarti H6 didukung. Hubungan level 
of information and complaining experience dan complaining behavior intention tidak dimoderasi oleh gender (jenis kelamin) wanita $(b=-0.044, p>0.05)$ dan pria $(b=-0.138, p>0.05)$, yang berarti $\mathrm{H} 7$ tidak didukung. Hubungan level of dissatisfaction dan complaining behavior intention dimoderasi oleh gender (jenis kelamin) wanita $(b=0.223, p<0.05)$ dan pria $(b=0.281$, $\mathrm{p}<0.05)$, yang berarti H8 didukung. Demikian pula hubungan importance of the situation dan complaining behavior intention dimoderasi oleh gender wanita $(b=-0.038, p>0.05)$ pria $(b=$ 0.012, $\mathrm{p}>0.05)$ yang berarti tidak mendukung H9. Akhirnya hubungan The likelihood of success with the complaint dan complaining behavior intention ternyata dimoderasi oleh gender wanita $(b=0.206, p<0.05)$ dan pria $(b=0.253, p<0.05)$, artinya hipotesis 10 didukung.

Hasil hipotesis satu menunjukkan bahwa ketika konsumen mengalami masalah, walaupun sebenarnya jasa yang dibeli tidak mahal, konsumen tetap ingin menyampaikan keluhan. Konsumen akan berusaha untuk berbicara dengan manajer restoran, meminta solusi terbaik bagi masalah yang dirasakannya, baik berupa kompensasi ataupun pengembalian uang. Bahkan konsumen tertentu mempunyai sikap yang cenderung selalu menyampaikan keluhan ketika ada masalah, walaupun konsumen lain mungkin tidak berkeinginan untuk mengeluhkannya. Konsumen tersebut sangat mungkin menyampaikan keluhan kepada temandan kerabatnya, bahkan bisa menyampaikan pada Lembaga lain seperti Yayasan Konsumen. Penemuan ini sesuai dengan penelitian yang dilakukan oleh Fernandes \& Santos (2007) pada industri restoran di Brazil, yang menemukan bahwa ketika sikap konsumen terhadap penyampaian keluhan positif, maka konsumen yang mengalami masalah akan berkeinginan untuk mengeluh pada restoran. Demikian pula hasil penelitian de Matos, Rossi, Veiga, \& Vieira (2009) menemukan bahwa konsumen dengan sikap terhadap keluhan yang tinggi akan sangat ingin menyampaikan keluhan ketika terjadi masalah pada jasa yang dikonsumsi.

The level of information and complaining experience tidak berpengaruh positif tehadap complaining behavior intention (H2). Hasil ini memperlihatkan bahwa walaupun konsumen mempunyai informasi yang cukup untuk menyampaikan keluhan, ternyata hal tersebut tidak mendorong mereka untuk menyampaikan keluhan, baik pada pengelola restoran ataupun pada pihak ketiga. Hasil hipotesis dua tidak sesuai dengan penelitian yang dilakukan oleh (Velázquez et al., 2010). Hal ini dapat disebabkan oleh perbedaan budaya, sebagaimana hasil penelitian Ekiz \& Au (2011) ketika membandingkan konsumen Cina dan Amerika, hasilnya ditemukan bahwa konsumen China cenderung lebih mudah memaafkan dan melupakan masalah sementara konsumen Amerika ingin menyampaikan keluhan kepada pihak ketiga. 
Hasil hipotesis tiga (H3) sesuai dengan penelitian yang dilakukan oleh Velázquez et al., (2010) bahwa terdapat pengaruh positif The level dissatisfaction terhadap complaining behavior intention. Hasil uji ini menunjukkan bahwa konsumen yang merasa bahwa kunjungan ke restoran tersebut tidak memuaskan, mereka akan memutuskan untuk tidak datang lagi ke restoran itu. Begitu juga konsumen yang berpendapat bahwa makan di restoran itu merupakan keputusan yang salah, sangat besar kemungkinannya untuk mendorong teman-temannya untuk tidak makan di restoran tersebut. Bahkan konsumen yang merasa menyesal telah makan di restoran itu, dapat menyampaikan keluhan melalui koran atau media sosial. Hal yang sama dilakukan oleh Fernandes \& Santos (2007) bahwa semakin besar ketidak puasan konsumen, maka semakin besar pula keinginan mereka untuk menyampaikan keluhan.

Hasil hipotesis empat (H4) menunjukkan bahwa semakin penting situasi yang dihadapi konsumen, maka semakin besar keinginan mereka untuk menyampaikan keluhan, baik secara langsung pada penyedia jasa, kepada pihak ketiga maupun secara tidak langsung. Ketika konsumen menganggap bahwa kunjungan mereka ke restoran ini sangat penting, maka saat menghadapi masalah konsumen akan segera menyampaikan keluhan tersebut pada manajemen. Bagi konsumen yang mengadakan acara penting di sebuah restoran, kegagalan pelayanan akan sangat mengesalkan dan mendorong mereka untuk menyampaikan keluhan secara dratis seperti menyampaikan ke Yayasan Konsumen, bahkan dapat menuntut restoran secara hukum. Hasil uji studi ini sejalan dengan Huppertz (2014) yang menegaskan bahwa semakin penting produk atau jasa terhadap diri konsumen, maka semakin besar keinginan konsumen untuk menyampaikan keluhan. Walaupun begitu, penemuan ini ternyata tidak sesuai dengan penelitian yang dilakukan oleh Velázquez et al., (2010) bahwa tidak terdapat pengaruh yang signifikan antara The importance of the situation terhadap complaining behavior intentions.

Hasil hipotesis lima (H5) menunjukkan bahwa ketika konsumen merasa yakin bahwa kemumgkinan keluhan mereka akan sukses mendapat perhatian dari perusahaan, maka semakin besar kemungkinan mereka untuk menyampaikan keluhan. Pada saat konsumen mempunyai keyakinan bahwa perusahaan sangat mungkin memperbaiki kegagalan yang dialaminya, maka konsumen bersedia berdiskusi dengan manajer perusahaan untuk mencari solusi bagi masalahnya. Begitu juga bila konsumen yakin bahwa pihak restoran akan menanggapi keluhannya, bersedia memastikan agar masalah yang sama tidak terjadi dimasa yang akan, maka mereka akan dengan senang hati menyampaikan masukan yang berguna bagi pihak restoran. Penemuan ini menarik, karena sesuai dengan studi sebelumnya yang menjelaskan bahwa kemungkinan sukses dalam menyampaikan keluhan menjadi salah satu factor yang mendorong konsumen bersedia melakukannya (Huppertz, 2014; Jin, 2010). Selain itu, hasil 
studi ini juga mendukung penelitian yang dilakukan oleh Velázquez et al., (2010) bahwa terdapat pengaruh yang signifikan antara The likelihood of success with the complaint terhadap complaining behavior.

Dalam penelitian ini, hasil pengujian hipotesis menunjukkan bahwa gender (jenis kelamin) memiliki peran moderasi. Hasil hipotesis enam (H6) menyatakan bahwa jenis kelamin, baik pria maupun wanita, memoderasi hubungan attitudes towards complaining terhadap complaining behavior intention. Namun pria lebih kuat memoderasi hubungan tersebut. Hal ini memperlihatkan bahwa pria mempunyai sikap yang lebih kuat terhadap keinginan menyampaikan keluhan. Pria ingin mendapatkan hasil yang jelas ketika mereka menghadapi masalah. Hasil ini sesuai dengan penelitian Gruber et al., (2009) yang menjelaskan bahwa konsumen pria ketika menghadapi masalah lebih mementingkan penanganan yang cepat.

Hasil pengujian hipotesis tujuh (H7) menunjukkan bahwa pria dan wanita tidak memoderasi hubungan level of information and complaining experience dan complaining behavior intention. Hal ini berarti, ketika konsumen menghadapi masalah, jenis kelamin tidak mempengaruhi keinginan mereka dalam menyampaikan keluhan. Hasil penelitian ini juga sesuai dengan pengujian hubungan langsung antara seberapa banyakpun informasi yang dimiliki konsumen dan juga pengalaman mereka dalam menyampaikan keluhan tidak dapat mendorong konsumen untuk bersungguh-sungguh memasukkan keluhan pada perusahaan. Rupanya konsumen wanita dan pria mempunyai persepsi yang sama dalam menyampaikan keluhan. Hasil studi ini sesuai dengan penelitian yang dilakukan di Australia, penemuan mereka menyatakan bahwa jenis kelamin ternyata tidak mempengaruhi keinginan konsumen untuk menyampaikan keluhan (Phau \& Baird, 2008).

Hipotesis delapan (H8) menyimpulkan bahwa jenis kelamin memang memoderasi hubungan level of dissatisfaction terhadap complaining behavior intentions. Hal ini menunjukkan bahwa pada tingkat ketidakpuasan yang sama, wanita dan pria memberikan dampak yang berbeda dalam keinginan menyampaikan keluhan. Terlihat bahwa pria lebih kuat dalam mempengaruhi hubungan tersebut karena pada saat mereka merasa tidak puas, konsumen pria akan cenderung lebih ingin menyampaikan kekesalan mereka. Bahkan menurut penelitian pada industry perhotelan, hasil studi menemukan bahwa konsumen pria yang merasa dikecewakan akan menyampaikan berita negatif kepada teman dan kerabatnya (Aguilar-Rojas et al., 2015). Walaupun hasil penelitian ini tidak sejalan dengan Song et al., (2017), karena dalam studi mereka mengenai respon wanita ketika mereka tidak puas terhadap kegagalan produk, menemukan bahwa ketika konsumen wanita merasa bahwa mereka sendirilah yang 
telah menyebabkan terjadi kegagalan pada produk yang mereka beli, maka ketidak puasannya menjadi lebih besar dan akan menyampaikan keluhannya kepada perusahaan.

Hasil pengujian hipotesis sembilan (H9) menunjukkan bahwa gender (jenis kelamin) tidak memoderasi hubungan importance of the situation terhadap complaining behavior intention. Sehingga dapat disimpulkan bahwa jenis kelamin tidak menyebabkan adanya perbedaan keinginan konsumen wanita ataupun pria menjadi lebih besar dalam menyampaikan keluhan. Walaupun konsumen pria atau wanita menggangap bahwa situasi mereka sangat penting ketika masalah terjadi, mereka akan tetap menyampaikan keluhan, hanya saja tidak terlihat bahwa konsumen wanita menjadi lebih kuat keinginannya, begitu juga konsumen pria. Hal ini tidak sesuai dengan penelitian yang dilakukan oleh Stratemeyer \& Geringer (2014) yang menjelaskan bahwa konsumen wanita segera mengeluhkan kegagalan pelayanan pada penyedia jasa dan meminta agar segera diperbaiki, permohonan maaf serta kompensasi. Sedangkan penelitian pada konsumen bank di Malasyia memperlihatkan bahwa konsumen pria dan wanita tidak memperlihatkan respon yang berbeda ketika mereka kecewa dengan pelayanan bank, sehingga menimbulkan keinginan untuk tidak lagi menggunakan jasa bank tersebut (Oly Ndubisi \& Yin Ling, 2006). Begitu juga penelitian pada pelayanan restoring "fine dining" menemukan bahwa konsumen pria ataupun wanita yang merasa dikecewakan menjadi sangat berkeinginan untuk menyampaikan keluhannya pada manajer restoran agar segera diperbaiki (Joe \& Choi, 2019)

Hasil pengujian sepuluh (H10) menunjukkan bahwa gender (jenis kelamin) memoderasi hubungan the likelihood of success with the complaint dan complaining behavior intention. Penelitian ini menemukan bahwa pria lebih kuat memoderasi hubungan tersebut. Hal ini berarti ketika konsumen pria merasa bahwa besar kemungkinan mereka akan sukses mendapat perbaikan dari perusahaan, maka semakin ingin konsumen tersebut menyampaikan keluhannya. Hasil studi ini sesuai dengan studi mengenai penggunaan social media untuk menyampaikan keluhan, ternyata konsumen pria yang mempunyai harapan tinggi untuk mendapatkan pemulihan masalah akan cenderung menyampaikan kekecewaannya melalui media social bila perbaikan masalah tidak sesuai harapannya (Yen, 2016).

\section{KESIMPULAN DAN SARAN}

Penelitian ini bertujuan untuk mengetahui faktor-faktor yang mempengaruhi (antecedents) complaining behavior intentions dan apakah gender (jenis kelamin) memoderasi antecedents tersebut. Hasil penelitian menunjukkan bahwa faktor-faktor yang mempengaruhi (Antecedents) complaining behavior intentions adalah attitudes towards complaining, the level 
of dissatisfaction, importance of the situation dan the likelihood of success with the complaint. Lebih lanjut, penelitian menunjukkan bahwa gender (jenis kelamin) memoderasi hubungan Attitudes towards complaining, level of dissatisfaction dan likelihood of success with the complaint terhadap complaining behavior intention.

\section{Implikasi Teoritis}

Hasil penelitian ini dapat memperkaya ilmu pengetahuan dalam bidang pemasaran jasa, khususnya mengenai perbaikan pelayanan ketika sebuah usaha jasa mengalami kegagalan. Konsumen akan berintensi untuk menyampaikan keluhan Ketika mereka mengalami kegagalan pelayanan. Ternyata tidak selalu konsumen ingin menyampaikan kekecewaannya, ada beberapa faktor yang dapat mendorong yaitu sikap konsumen mengenai penyampaian keluhan, tingkat kekecewaan yang dirasakan konsumen, seberapa penting pelayanan jasa yang mereka harapkan dan juga tingkat kesuksesan dalam mendapat pemulihan pelayanan. Bila faktorfaktor ini ada pada konsumen, barulah mereka ingin mengeluhkan kegagalan yang mereka rasakan.

Selain itu, penelitian ini juga dapat menambahkan bahwa jenis kelamin mempunyai peranan yang penting dalam proses penyampaian keluhan. Jenis kelamin dapat memoderasi keinginan konsumen untuk menyampaikan keluhan, terutama ketika konsumen memang mempunyai sikap positif dalam mengeluhkan masalah yang dihadapi, lalu saat konsumen merasa masalah yang dihadapi memang sangat mengesalkan dan akhirnya saat konsumen merasa yakin bahwa keluhannya akan ditanggapi dengan baik oleh perusahaan.

\section{Implikasi Manajerial}

Penelitian ini mempunyai beberapa implikasi manajerial yang dapat digunakan oleh manajer restoran dalam upaya untuk mengurangi kegagalan jasa dan meningkatkan kualitas layanan serta dapat meningkatkan kepuasan pengunjung restoran. Dalam penanganan komplen perusahaan dapat menerapkan perilaku keadilan (perceived justice behavior) dengan cara membuat prosedur penyampaian keluhan yang mudah dipahami, melatih karyawan untuk selalu bersikap ramah dan mengembangkan konpensasi yang jelas. Peningkatan food service quality meliputi kesegaran makanan, tampilan makanan, suasana restoran dan interaksi karyawan merupakan hal yang mutlak harus diperhatikan dan ditingkatkan.

Lebih lanjut, perhatian terhadap pengunjung pria dan wanita harus diperhatikan harus dibedakan karena pelayanan terhadap pria berbeda dengan wanita. Ketika terjadi kegagalan pelayanan terhadap konsumen wanita, maka perusahaan harus segera menyampaikan permintaan maaf dan berusaha mengurangi kemarahan konsumen, mengingat wanita 
cenderung lebih emosional dibandingkan laki-laki (Gruber et al., 2009). Selain itu, sangat penting bagi perusahaan jasa untuk membina hubungan baik dengan konsumen wanita, mengingat bahwa mereka akan lebih mudah memaafkan kesalahan pelayanan bila telah terjalin hubungan baik (Yagil \& Luria, 2016).

Sebaliknya konsumen laki-laki tidak terlalu mementingkan permintaan maaf yang terlalu berlebihan, bagi mereka penyelesaian yang cepat lebih penting (Gruber et al., 2009). Oleh sebab itu, apabila terjadi kegagalan pelayanan, penyedia jasa harus segera memperbaiki masalah inti yang terjadi (Gruber et al., 2009). Selain itu, konsumen laki-laki lebih senang membaca dan juga memberikan ulasan yang bersifat umum, tanpa harus menulis panjang mengenai pelayanan yang diberikan (Zhang et al., 2018). Oleh sebab itu sebaiknya perusahaan jasa menyediakan suatu bentuk formulir yang memudahkan konsumen untuk menyampaikan ulasan ataupun keluhan seperti dokumen google form ataupun berbagai model survey secara online.

\section{Keterbatasan dan Saran untuk Peneliti selanjutnya}

Penelitian ini memiliki beberapa keterbatasan. Pertama, penelitian ini hanya meneliti industri restoran sehingga diharapkan penelitian selanjutnya dapat meneliti industri lain seperti perhotelan dan pariwisata mengingat bahwa kegagalan penyampaian jasa sangat mungkin terjadi pada pelayanan hotel maupun wisata. Kedua, penelitian ini menggunakan 5 (lima) variabel antecedents dari complaining behavior intentions. Untuk penelitian selanjutnya diharapkan dapat menambahkan variabel lain seperti Perceived Justice Behaviour mengingat bahwa persepsi konsumen terhadap keadilan yang dilakukan perusahaan jasa sangat mempengaruhi kepuasan konsumen (Mattila et al., 2011). 


\section{DAFTAR PUSTAKA}

Aguilar-Rojas, O., Fandos-Herrera, C., \& Flavián-Blanco, C. (2015). What may lead you to recommend and revisit a hotel after a service failure instead of complaining? International Journal of Contemporary Hospitality Management, 27(2), 214-235. https://doi.org/10.1108/IJCHM-06-2013-0265

Audrain-Pontevia, A.-F., \& Vanhuele, M. (2016). Where do customer loyalties really lie, and why? Gender differences in store loyalty. International Journal of Retail \& Distribution Management, 44(8), 799-813. https://doi.org/10.1108/IJRDM-01-2016-0002

Ayas, M., Manzoor, S. R., \& Khan, A. (2016). Factors affecting restaurant image in KPK , Pakistan : Moderating role of Personality trait. Journal of Business Trategies, 10(2), 127140.

Blodgett, J., Bakir, A., Saklani, A., \& Bachheti, M. (2015). Customer Complaint Behavior: an Examination of Cultural Vs. Situational Factors. Journal of Consumer Satisfaction/Dissatisfaction \& Complaining Behavior, 28, 61-74.

Blodgett, J. G., Granbois, D. H., \& Walters, R. G. (1993). The effects of perceived justice on complainants' Negatif Word-of Mouth Behavior and Repatronage Intentions. Journal of Retailing, 69(4), 399-428.

Bolfing, C. P. (1989). How do Customers Express Dissatisfaction and what can Service Marketers do about it? Journal of Services Marketing, 3(2), 5-23. https://doi.org/10.1108/EUM0000000002483

Chelminski, P., \& Coulter, R. A. (2011). An examination of consumer advocacy and complaining behavior in the context of service failure. Journal of Services Marketing, 25(5), 361-370. https://doi.org/10.1108/08876041111149711

Cooper, D. R., \& Schindler, P. S. (2014). Business Research Methods 12th Edition. In Business Research Methods. The McGraw-Hill/Irwin Series.

de Matos, C. A., Henrique, J. L., \& de Rosa, F. (2013). Customer reactions to service failure and recovery in the banking industry: The influence of switching costs. Journal of Services Marketing, 27(7), 526-538. https://doi.org/10.1108/JSM-01-2012-0019

de Matos, C. A., Rossi, C. A. V., Veiga, R. T., \& Vieira, V. A. (2009). Consumer reaction to service failure and recovery: The moderating role of attitude toward complaining. Journal of Services Marketing, 23(7), 462-475. https://doi.org/10.1108/08876040910995257

Edvardsson, B., Tronvoll, B., \& Höykinpuro, R. (2011). Complex service recovery processes: how to avoid triple deviation. Managing Service Quality: An International Journal, 21(4), 331-349. https://doi.org/10.1108/09604521111146234 
Ekiz, E. H., \& Au, N. (2011). Comparing Chinese and American attitudes towards complaining. International Journal of Contemporary Hospitality Management, 23(3), 327-343. https://doi.org/10.1108/09596111111122514

Faqih, K. M. S., \& Jaradat, M. I. R. M. (2015). Assessing the moderating effect of gender differences and individualism-collectivism at individual-level on the adoption of mobile commerce technology: TAM3 perspective. Journal of Retailing and Consumer Services, 22, 37-52. https://doi.org/10.1016/j.jretconser.2014.09.006

Fernandes, D. V. der H., \& Santos, C. P. (2007). Consumer Complaining Behavior in Developing Countries: The case of Brazil. Journal of Consumer Satisfaction, Dissatisfaction and Complaining Behavior, 20, 86-109.

Frank, B., Enkawa, T., \& Schvaneveldt, S. J. (2014). How do the success factors driving repurchase intent differ between male and female customers? Journal of the Academy of Marketing Science, 42(2), 171-185. https://doi.org/10.1007/s11747-013-0344-7

Funches, V. (2011). The consumer anger phenomena: causes and consequences. Journal of Services Marketing, 25(6), 420-428. https://doi.org/10.1108/08876041111161014

Funches, V., Markley, M., \& Davis, L. (2009). Reprisal, retribution and requital: Investigating customer retaliation. Journal of Business Research, 62(2), 231-238. https://doi.org/10.1016/j.jbusres.2008.01.030

Gangai, K. N., \& Agrawal, R. (2016). The Influence of Personality Traits on Consumer Impulsive Buying Behaviour. International Journal of Marketing and Business Communication, 5(1). https://doi.org/10.21863/ijmbc/2016.5.1.027

Gruber, T., Szmigin, I., \& Voss, R. (2009). Handling customer complaints effectively: A comparison of the value maps of female and male complainants. Managing Service Quality: An International Journal, 19(6), 636-656. https://doi.org/10.1108/09604520911005044

Hair, J. F., Black, W. C., Babin, B. J., \& Anderson, R. E. (2019). Multivariate Data Analysis : Multivariate Data Analysis: Why multivariate data analysis? (8th ed.). Cengage Learning.

Hamzelu, B., Gohary, A., Ghafoori Nia, S., \& Heidarzadeh Hanzaee, K. (2017). Does involvement shapes consumers' response to product failure? Asia Pacific Journal of Marketing and Logistics, 29(2), 283-304. https://doi.org/10.1108/APJML-03-2016-0042

Huang, W., \& Lin, T. (2011). Developing effective service compensation strategies. Journal of Service Management, 22(2), 202-216. https://doi.org/10.1108/09564231111124226

Huppertz, J. W. (2014). an Effort Model of First-Stage Complaining Behavior. Journal of 
Consumer Satisfaction, Dissatisfaction \& Complaining Behavior, 27, 6-18.

Jin, L. (2010). Determinants of customers' complaint intention. Nankai Business Review International, 1(1), 87-99. https://doi.org/10.1108/20408741011032872

Joe, S., \& Choi, C. (2019). The effect of fellow customer on complaining behaviors: the moderating role of gender. International Journal of Contemporary Hospitality Management, 31(8), 3116-3133. https://doi.org/10.1108/IJCHM-09-2018-0717

Leppäniemi, M., \& Karjaluoto, H. (2008). Exploring the effects of gender, age, income and employment status on consumer response to mobile advertising campaigns. Journal of Systems and Information Technology, 10(3), 251-265. https://doi.org/10.1108/13287260810916943

Levesque, T. J., \& McDougall, G. H. G. (1996). Customer Dissatisfaction: The Relationship between Types of Problems and Customer Response. Canadian Journal of Administrative Sciences, 13(3), 264-276. https://doi.org/10.1111/j.1936-4490.1996.tb00736.x

Mattila, A. S., Cho, W., \& Ro, H. (2011). The role of self-service technologies in restoring justice. Journal of Business Research, 64(4), 348-355. https://doi.org/10.1016/j.jbusres.2010.02.014

Maxham, J. G., \& Netemeyer, R. G. (2002). A Longitudinal Study of Complaining Customers' Evaluations of Multiple Service Failures and Recovery Efforts. Journal of Marketing, 66(4), 57-71. https://doi.org/10.1509/jmkg.66.4.57.18512

McQuilken, L. (2009). The Influence of Failure Severity and Perceived Employee Effort on Consumers' Postcomplaint Negatif WOM Intentions in a Service Guarantee Context. Australian and New Zealand Marketing Academy Conference, 1-9.

Meng, F., Wang, S., Peters, S., \& Lawson, G. W. (2010). a Glimpse Into the Consumer. Journal of Consumer Satisfaction, Dissatisfaction \& Complaining Behavior, 23, 111-133.

Oh, D. G. (2006). Complaining intentions and their relationships to complaining behavior of academic library users in South Korea. Library Management, 27(3), 168-189. https://doi.org/10.1108/01435120610652914

Oly Ndubisi, N., \& Yin Ling, T. (2006). Complaint behaviour of Malaysian consumers. Management Research News, 29(1), 65-76. https://doi.org/10.1108/01409170610645457

Phau, I., \& Baird, M. (2008). Complainers versus non-complainers retaliatory responses towards service dissatisfactions. Marketing Intelligence and Planning, 26(6), 587-604. https://doi.org/10.1108/02634500810902848 
Singh, J. (1988). Consumer Complaint Intentions and Behavior: Definitional and Taxonomical Issues. Journal of Marketing, 52(1), 93. https://doi.org/10.2307/1251688

Singh, J. (1990). Voice, exit, and negatif word-of-mouth behaviors: An investigation across three service categories. Journal of the Academy of Marketing Science, 18(1), 1-15. https://doi.org/10.1007/BF02729758

Singh, J. (1991). Industry Characteristics and Consumer Dissatisfaction. Journal of Consumer Affairs, 25(1), 19-56. https://doi.org/10.1111/j.1745-6606.1991.tb00279.x

Singh, J., \& Wilkes, R. E. (1996). When consumers complain: A path analysis of the key antecedents of consumer complaint response estimates. Journal of the Academy of Marketing Science, 24(4), 350-365. https://doi.org/10.1177/0092070396244006

Singh, V., Jain, A., \& Choraria, S. (2016). Exploring the Role of Complaint Handling among Complaining Consumers. Vision, 20(4), 331-344. https://doi.org/10.1177/0972262916668739

Song, S., Sheinin, D. A., \& Yoon, S. (2017). When women are dissatisfied: Gender differences in product failure attribution. Social Behavior and Personality: An International Journal, 45(8), 1397-1408. https://doi.org/10.2224/sbp.6169

Stratemeyer, A. W., \& Geringer, S. D. (2014). An Exploratory Investigation of the Effects of Service Failures and Recovery Efforts on Customer Satisfaction California State University, Fresno. 14(1988), 20-29.

Tahir, H. M., Buttar, Z. A., \& Ahmad, I. (2018). Consumer Complaint Behavior and Defection : The Moderating Role of Demographic Factors and Switching Cost. The IUP Journal of Marketing Management, 17(2), 58-80.

Tifferet, S., \& Herstein, R. (2012). Gender differences in brand commitment, impulse buying, and hedonic consumption. Journal of Product and Brand Management, 21(3), 176-182. https://doi.org/10.1108/10610421211228793

Tsarenko, Y., \& Rooslani Tojib, D. (2011). A transactional model of forgiveness in the service failure context: a customer-driven approach. Journal of Services Marketing, 25(5), 381392. https://doi.org/10.1108/08876041111149739

Velázquez, B. M., Blasco, M. F., Saura, I. G., \& Contrí, G. B. (2010). Causes for complaining behaviour intentions: The moderator effect of previous customer experience of the restaurant. Journal of Services Marketing, 24(7), 532-545. https://doi.org/10.1108/08876041011081087

Wulandari, H. (2015). [Statistik Rumah Makan 2015]. In Badan Pusat Statistik. 
Yagil, D., \& Luria, G. (2016). Customer forgiveness of unsatisfactory service: manifestations and antecedents. Service Business, 10(3), 557-579. https://doi.org/10.1007/s11628-0150282-1

Ye, L., Bose, M., \& Pelton, L. E. (2017). How Gender Identity Affect Consumer Behavior: Overview and Historical Analysis. Journal Of Business Diversity, 17(4), 9-24.

Yen, Y. S. (2016). Factors enhancing the posting of negatif behavior in social media and its impact on venting negatif emotions. Management Decision, 54(10), 2462-2484. https://doi.org/10.1108/MD-11-2015-0526

Zhang, Z., Li, H., Meng, F., \& Qiao, S. (2018). Gender difference in restaurant online booking timing and the moderating effects of sell-out risk and information type. Journal of Electronic Commerce Research, 19(3), 266-279. 